\title{
Factors associated with early antenatal care attendance among women in Papua New Guinea: a population-based cross-sectional study
}

\author{
Abdul-Aziz Seidu ${ }^{1,2}$ (D)
}

\begin{abstract}
Background: Early initiation of antenatal care (ANC) is a key component of antenatal care, as suggested by the World Health Organisation (WHO). It helps in early identification and mitigation of adverse pregnancy-related complications. Despite this, a greater proportion of women worldwide still do not adhere to this recommendation. This study, therefore, sought to assess the prevalence and factors associated with early initiation of ANC among women in Papua New Guinea (PNG).

Methods: A population-based cross-sectional study was conducted among 4,274 women using data from the 2016-2018 PNG Demographic and Health Survey (PDHS). The outcome variable was early initiation of ANC. Bivariate (chi-square) and multivariable logistic regression analyses were done and statistical significance was set at $p<0.05$.

Results: The prevalence of early ANC initiation was $23.0 \%(C l=20.8-24.6)$. The binary logistic regression analysis showed that working women had higher odds of early ANC attendance compared with those who were not working $[A O R=1.37,95 \% \mathrm{Cl}=1.17=1.60]$. The results also showed that women from Islands region had lower odds $[A O R=0.50,95 \% \mathrm{Cl}=0.40-0.62]$ of early ANC attendance compared with those from Southern region. Finally, women with parity 3 had lower odds of early ANC attendance compared to those with parity 1 [AOR $=0.64,95 \%$ $\mathrm{Cl}=0.49-0.84]$.

Conclusions: This study found a relatively low prevalence of early ANC uptake among women in PNG. The factors associated with early ANC attendance were region of residence, parity, and working status of mothers. To increase early ANC uptake, these factors should be considered when designing new policies or reviewing policies and strategies on ANC uptake to help increase ANC attendance, which can help in the reduction of maternal mortality.
\end{abstract}

Keywords: Antenatal care, Initiation, Papua New Guinea, Public Health, Pregnant women, Timing, Utilisation

Correspondence: abdul-aziz.seidu@stu.ucc.edu.gh

'Department of Population and Health, College of Humanities and Legal

Studies, University of Cape Coast, Cape Coast, Ghana

${ }^{2}$ College of Public Health, Medical and Veterinary Sciences, James Cook

University, Townsville, Queensland, Australia

(c) The Author(s). 2021 Open Access This article is licensed under a Creative Commons Attribution 4.0 International License, which permits use, sharing, adaptation, distribution and reproduction in any medium or format, as long as you give appropriate credit to the original author(s) and the source, provide a link to the Creative Commons licence, and indicate if changes were made. The images or other third party material in this article are included in the article's Creative Commons licence, unless indicated otherwise in a credit line to the material. If material is not included in the article's Creative Commons licence and your intended use is not permitted by statutory regulation or exceeds the permitted use, you will need to obtain permission directly from the copyright holder. To view a copy of this licence, visit http://creativecommons.org/licenses/by/4.0/. The Creative Commons Public Domain Dedication waiver (http://creativecommons.org/publicdomain/zero/1.0/) applies to the data made available in this article, unless otherwise stated in a credit line to the data. 


\section{Background}

Globally, maternal mortality is one of the major public health concerns [1]. As a result, it featured in the past Millennium Development Goals (MDGs) and well featured in its successor, Sustainable Development Goals (SDG) target 3.1. Antenatal care during pregnancy is one of the measures to reduce maternal mortality [2]. Gebresilassie et al. [3] defined first timing of antenatal care (ANC) attendance "as the first-time pregnant women come to antenatal clinics to get care from health care professionals". During this period, health providers can determine the health status of the mother and the foetus. The WHO [4] recommends that pregnant women in low- and middle-income countries (LMICs) get at least four ANC visits and initiate early ANC follow-ups. In the light of the evidence-based benefits of $\mathrm{ANC}$, in 2016, the WHO recommended eight visits for women in low- and middle-income countries, rather than the four recommended previously [5]. The 1st ANC timing should be before 16 weeks of gestational age (early ANC attendance or initiation), the 2nd visit between 24 and 28 weeks of gestation age, the 3rd visit between 30 and 32 weeks gestational age, and the 4th visit between 36 and 38 weeks of gestational age. This early initiation of ANC is critical to aid in early detection of pregnancy-related problems and adverse pregnancy outcomes, including low birth weight, still birth, intra uterine foetal death, and other complications [3-6].

Worldwide, approximately 830 and more than 303,000 women die each day and annually respectively due to pregnancy and childbirth-related complications [1]. From these numbers, the greater percentage (99\%) occur in LMICs [1, 7]. Papua New Guinea (PNG) is one of the Asian Pacific countries with the highest maternal mortality ratios $[8,9]$ and the major causes of these deaths are obstetric haemorrhage, sepsis, embolism, eclampsia and unsafe abortion [8]. Some of these complications can be detected through early initiation of ANC. Despite this, in many LMICs, women do not attend ANC at all or start seeking ANC late during pregnancy $[3,10]$, with global prevalence of $58.6 \%$ (48.1\% in developing regions and $84.8 \%$ in developed regions as well as $81.9 \%$ in high-income countries and $24.0 \%$ in lowincome countries) [11].

Evidence suggests that age $[6,12,13]$, wealth status [6, $14]$, work or employment $[12,15]$, level of education of women and their partners $[3,6,12-14]$, marital status [12], place and region of residence [16], parity [17], pregnancy intentions [3,12-15, 17], sex of household head, exposure to mass media [18], decision maker on healthcare, permission before seeking healthcare, money to seek healthcare, and distance to health facility [17] are associated with early ANC. These studies conducted in various parts of the world have consistently found a low level of early ANC initiation. Despite this evidence, to the best of my knowledge, none of such studies have been conducted in PNG using nationally representative dataset to determine the prevalence and factors associated with early initiation of ANC. The findings of such a national study would be critical because they will aid in identifying particular women to target in order to increase the use of ANC services, which can help reduce maternal mortality in PNG.

\section{Materials and methods \\ Data and sampling design}

The data used for this study forms part of the 20162018 PDHS, which was collected from October 2016 to December 2018. The survey adopted a two-stage stratified sampling technique. Each province was stratified into urban and rural areas, yielding 43 sampling strata, with the exception of National Capital District, which had no rural area. Samples of census units (CUs) were selected independently in each stratum in two stages. In the first stage, 800 CUs were selected with probability proportional to CU size, which is the number of residential households found in the CU during the 2011 National Population and Housing Census (NPHC) [19]. Some of the selected clusters were large, with more than 200 households. To minimise the task of the listing team, these selected clusters were segmented. Only one segment was selected for the survey, with probability proportional to segment size. Household listing was conducted only in the selected segment. This means that a cluster is either a CU or a segment of a CU. In the second stage of selection, a fixed number of 24 households per cluster were selected with an equal probability systematic selection from the newly created household listing, resulting in a total sample size of approximately 19,200 households. All women aged 15-49 who were usual members of the selected households or who spent the night before the survey in the selected households were eligible for individual interview. A total of 17,505 households were selected for the sample, of which 16,754 were occupied and 16,021 were successfully interviewed ( $96 \%$ response rate). In the interviewed households, 18,175 women age 15-49 were identified for individual interviews but 15,198 women were reached (84\% response rate). The final sample size for this study consists of 4,274 women who indicated they had ever attended ANC prior to the survey. Details of the methodology, pretesting, training of field workers, the sampling design, and selection are available in the PDHS final report [19] which is also available online at https://dhsprogram.com/publications/ publication-fr364-dhs-final-reports.cfm.

\section{Derivation of study variables Outcome variable}

The outcome variable for this study is ANC attendance. It was derived it from the question "How many months 
pregnant were you when you first received antenatal care for this pregnancy?" The responses were in months. It was then dichotomised to early initiation of $\mathrm{ANC}=$ " 1 " if women reported attending at 3 months or earlier and Late initiation= "0", after 3 months [6, 13, 15, 17, 18, 20].

\section{Independent variables}

Eighteen independent variables were considered in this study. They were chosen based on two reasons, thus, their availability in the dataset [19] and conclusion drawn on them to be associated with ANC attendance in previous studies $[6,13,15,17,18,20]$. The variables comprised maternal age, wealth, working status, education, partner's education, marital status, place of residence, region of residence, parity, pregnancy intention, permission to go to hospital, getting money for treatment, distance to health facility, frequency of listening to radio, frequency of watching television, frequency of reading newspaper or magazine, and sex of household head. Some of these variables were recoded for meaningful, easy interpretation of results. Parity (birth order) was categorised as one birth= " 1 ", two births = "2", three births $=$ " 3 " and four births or more $=$ " 4 ". Occupation was captured as working= " 1 " and not working= " 0 " and decision maker on healthcare was captured as alone $=$ " 1 " and not alone $=$ "2" (see Table 1$)$.

\section{Statistical analyses}

Descriptive, bivariate and multiple logistic regression analyses were conducted. The descriptive analysis (frequencies and percentages) was used to describe the study sample. The bivariate analysis was conducted using Chi-square test to assess the differentials in the prevalence of early ANC attendance across all the independent variables. All the variables that appeared statistically significant $(p<0.05)$ were moved to the multiple logistic regression analysis stage. The results for the multiple logistic regression analysis were presented as adjusted odds ratios (AOR) along with their respective $95 \%$ confidence intervals (CIs) signifying precision. Using the variance inflation factor (VIF), I found that the multicollinearity test showed no evidence of collinearity among the independent variables (Mean VIF $=1.4$, Max VIF $=1.72$, Minimum =1.01). The sample weight (wt) was used to account for the complex survey (svy) design and generalizability of the findings. All the analyses were done with Stata version 14.2 for MacOS.

\section{Ethical issues}

The 2016-2018 PDHS report indicated that ethical approval was granted by the ICF Institutional Review Board [18]. Both written and verbal informed consent were also sought from all the participants during the data collection exercise. The dataset was requested on 10th March, 2020.The dataset can be accessed at: https://dhsprogram.com/data/dataset/Papua-NewGuinea_Standard-DHS_2017.cfm?flag=0.

\section{Results}

Table 1 presents the prevalence of early ANC attendance among women who sought ANC at PNG. It was found that less than a quarter $(23 \%)$ had initiated ANC attendance early. Table 1 also shows the background characteristics of the women. It was found that $27 \%$ were aged 25-29. Approximately $23 \%$ were in the richest wealth category and $64.3 \%$ were not working. Slightly more than half $(51.2 \%)$ have attained primary level of education. The majority $(83.5 \%)$ were married. The majority $(87.0 \%)$ were also in rural areas while $36.4 \%$ had 4 or more children. It was also found that $24.8 \%$ of the women aged 20-24 had initiated ANC attendance within the first trimester. It was also found that $25.4 \%$ of the poorest, $23.5 \%$ of those working, $25.9 \%$ of those with no formal education and $21.4 \%$ of those who were married initiated their ANC early (see Table 1).

\section{Determinants of early ANC attendance among women in PNG}

Table 2 presents the logistic regression analysis of determinants of early ANC attendance among women in PNG. It was found that working women had about 1.37 higher odds of early ANC attendance compared with those who were not working $[\mathrm{AOR}=1.37$, $95 \% \mathrm{CI}=$ $1.17=1.60]$. The results also showed that women from Islands region had 0.50 lower odds $[\mathrm{AOR}=0.50$, $95 \% \mathrm{CI}=0.40-0.62]$ of early ANC attendance compared with those from Southern region. Finally, women with parity 3 had 0.64 lower odds of early ANC attendance compared to those with parity $1[\mathrm{AOR}=0.64,95 \% \mathrm{CI}=$ 0.49-0.84].

\section{Discussion}

This study sought to assess the prevalence and determinants of early initiation of ANC attendance among women in PNG. The WHO [4] recommends that every woman should make an effort to attend ANC within the first trimester due to the fact that it is one of the critical stages during pregnancy. Despite this recommendation, a greater number of women in most LMICs do not adhere to this recommendation $[6,20]$. In this current study, less than a quarter (23\%) of women in PNG initiated ANC attendance in their first trimester during pregnancy. This is similar in several LMICs including Ethiopia (21.7\%) [17], (27.5\%) [3, 21], (26.2\%) [21]; Benin (24.6\%) [22]; Tanzania (29\%) [23] and Uganda (27.9\%) [24]. The prevalence of early ANC initiation in 
Table 1 Background characteristics and early ANC attendance among women in PNG

\begin{tabular}{|c|c|c|c|c|}
\hline \multirow[t]{2}{*}{ Variable } & \multicolumn{2}{|l|}{$N=4,274$} & \multicolumn{2}{|c|}{ Early ANC attendance } \\
\hline & Frequency & Percentage & $\begin{array}{l}\text { No (\%) } \\
3306(77.0 \%)\end{array}$ & $\begin{array}{l}\text { Yes (\%) } \\
968(23 \%)\end{array}$ \\
\hline \multicolumn{5}{|c|}{ Age $\left(x^{2}=13.3, p=0.038\right)$} \\
\hline $15-19$ & 156 & 3.6 & 77.6 & 22.5 \\
\hline $20-24$ & 969 & 22.7 & 75.2 & 24.8 \\
\hline $25-29$ & 1,156 & 27.0 & 78.9 & 21.1 \\
\hline $30-34$ & 906 & 21.2 & 81.7 & 18.3 \\
\hline $35-39$ & 658 & 15.4 & 78.5 & 21.5 \\
\hline $40-44$ & 340 & 8.0 & 79.5 & 20.5 \\
\hline $45-49$ & 89 & 2.1 & 83.9 & 16.1 \\
\hline \multicolumn{5}{|c|}{ Wealth $\left(x^{2}=14.0, p=0.007\right)$} \\
\hline Poorest & 641 & 15.0 & 74.7 & 25.4 \\
\hline Poorer & 787 & 18.4 & 76.0 & 24.0 \\
\hline Middle & 881 & 20.6 & 78.5 & 21.5 \\
\hline Richer & 947 & 22.2 & 81.6 & 18.4 \\
\hline Richest & 1,018 & 23.8 & 79.6 & 20.4 \\
\hline \multicolumn{5}{|c|}{ Working $\left(x^{2}=9.1, p=0.003\right)$} \\
\hline Not working & 2,746 & 64.3 & 80.3 & 19.7 \\
\hline Working & 1,528 & 35.7 & 76.5 & 23.5 \\
\hline \multicolumn{5}{|c|}{ Education $\left(x^{2}=16.9, p=0.001\right)$} \\
\hline No education & 757 & 17.7 & 74.2 & 25.9 \\
\hline Primary & 2,189 & 51.2 & 80.0 & 20.0 \\
\hline Secondary & 1091 & 25.5 & 80.1 & 19.9 \\
\hline Higher & 237 & 5.5 & 72.3 & 27.8 \\
\hline \multicolumn{5}{|c|}{ Partner Education $\left(x^{2}=7.30, p=0.063\right)$} \\
\hline No education & 663 & 15.5 & 75.8 & 24.2 \\
\hline Primary & 1,774 & 41.5 & 79.5 & 20.5 \\
\hline Secondary & 1,396 & 32.7 & 80.0 & 20.1 \\
\hline Higher & 441 & 10.3 & 75.6 & 24.4 \\
\hline \multicolumn{5}{|c|}{ Marital status $\left(x^{2}=0.83, p=0.362\right)$} \\
\hline Married & 3,570 & 83.5 & 78.6 & 21.4 \\
\hline Cohabiting & 704 & 16.5 & 80.1 & 19.9 \\
\hline \multicolumn{5}{|c|}{ Region $\left(x^{2}=66.7, p<0.001\right)$} \\
\hline Southern region & 922 & 21.6 & 76.7 & 23.3 \\
\hline Highlands region & 1,579 & 37.0 & 73.4 & 26.7 \\
\hline Momase region & 1,082 & 25.3 & 78.1 & 21.9 \\
\hline Islands region & 690 & 16.2 & 86.9 & 13.1 \\
\hline \multicolumn{5}{|c|}{ Residence $\left(x^{2}=1.2, p=0.278\right)$} \\
\hline Urban & 555 & 13.0 & 80.0 & 20.1 \\
\hline Rural & 3,719 & 87.0 & 78.4 & 21.6 \\
\hline \multicolumn{5}{|c|}{ Parity $\left(x^{2}=20.0, p<0.001\right)$} \\
\hline 1 & 1,034 & 24.2 & 75.3 & 24.7 \\
\hline 2 & 903 & 21.1 & 76.7 & 23.4 \\
\hline 3 & 781 & 18.3 & 83.0 & 17.0 \\
\hline
\end{tabular}


Table 1 Background characteristics and early ANC attendance among women in PNG (Continued)

\begin{tabular}{|c|c|c|c|c|}
\hline \multirow[t]{2}{*}{ Variable } & \multicolumn{2}{|l|}{$N=4,274$} & \multicolumn{2}{|c|}{ Early ANC attendance } \\
\hline & Frequency & Percentage & $\begin{array}{l}\text { No }(\%) \\
3306(77.0 \%)\end{array}$ & $\begin{array}{l}\text { Yes (\%) } \\
968(23 \%)\end{array}$ \\
\hline $4+$ & 1,556 & 36.4 & 80.2 & 19.8 \\
\hline \multicolumn{5}{|c|}{ Pregnancy intention $\left(x^{2}=1.4, p=0.490\right)$} \\
\hline Planned & 3,001 & 70.2 & 79.3 & 20.8 \\
\hline Mistimed & 526 & 12.3 & 77.0 & 23.0 \\
\hline Unwanted & 747 & 17.5 & 78.4 & 21.6 \\
\hline \multicolumn{5}{|c|}{ Permission to go to hospital $\left(x^{2}=0.6, p=0.453\right)$} \\
\hline Big problem & 1,210 & 28.3 & 79.6 & 20.4 \\
\hline Not a big problem & 3,064 & 71.7 & 78.5 & 21.5 \\
\hline \multicolumn{5}{|c|}{ Getting money needed for treatment $\left(x^{2}=2.10, p=0.147\right)$} \\
\hline Big problem & 2,521 & 59.0 & 78.0 & 22.0 \\
\hline Not a big problem & 1,753 & 41.0 & 79.9 & 20.1 \\
\hline \multicolumn{5}{|c|}{ Distance to health facility $\left(X^{2}=2.44, p=0.118\right)$} \\
\hline Big problem & 2,275 & 53.2 & 77.8 & 22.2 \\
\hline Not a big problem & 1,999 & 46.8 & 79.8 & 20.2 \\
\hline \multicolumn{5}{|c|}{ Decision maker on healthcare $\left(x^{2}=0.0, p=1.00\right)$} \\
\hline Not alone & 2,996 & 70.1 & 78.8 & 21.2 \\
\hline Alone & 1,278 & 29.9 & 78.8 & 21.2 \\
\hline \multicolumn{5}{|c|}{ Frequency of reading newspaper or magazine $\left(x^{2}=7.4, p=0.025\right)$} \\
\hline Not at all & 2,566 & 60.0 & 77.8 & 22.2 \\
\hline Less than once a week & 930 & 21.8 & 81.9 & 18.1 \\
\hline At least once a week & 778 & 18.2 & 78.1 & 21.9 \\
\hline \multicolumn{5}{|c|}{ Frequency of listening to radio $\left(\chi^{2}=4.5, p=0.106\right)$} \\
\hline Not at all & 2,622 & 61.3 & 79.3 & 20.7 \\
\hline Less than once a week & 870 & 20.4 & 80.0 & 20.0 \\
\hline At least once a week & 782 & 18.3 & 76.2 & 23.8 \\
\hline \multicolumn{5}{|c|}{ Frequency of watching television $\left(x^{2}=1.8, p=0.413\right)$} \\
\hline Not at all & 3,188 & 74.6 & 79.3 & 20.7 \\
\hline Less than once a week & 439 & 10.3 & 77.8 & 22.2 \\
\hline At least once a week & 647 & 15.1 & 77.3 & 22.8 \\
\hline \multicolumn{5}{|c|}{ Sex of household head $\left(x^{2}=0.2, p=0.670\right)$} \\
\hline Male & 3,669 & 85.8 & 78.7 & 21.3 \\
\hline Female & 605 & 14.2 & 79.5 & 20.5 \\
\hline
\end{tabular}

Source: 2016-18 PNG DHS

this study is, however, higher than what was found in other studies done in Zambia (17\%) [25], Nigeria (15.4\%) [26], Tanzania (12.4\%) [27], and Ethiopia (17.4\%) [20], (13.2\%) [28].

Nonetheless, the prevalence recorded in this study is lower than the global prevalence of $58.6 \%$ [11] as well as several other studies elsewhere showing prevalence between 32.7 and $72 \%$ [6, 12, 14-17, 29-32]. The differences in the study findings could be explained by the differences in study settings. This lower proportion of early ANC uptake in this study implies that most women in PNG may not enjoy full importance associated with early ANC uptake [6, 11]. Some of these benefits include precautionary measures, timely disease detection and treatment strategies, including use of iron and folate supplements for the treatment of anaemia, Intermittent Preventive Treatment for malaria in pregnancy, immunisation against tetanus and Tuberculosis, and detection of Sexually Transmitted Infections including HIV and AIDS to prevent mother to child transmission as well as health education in general including appropriate nutrition and personal hygiene $[6,11]$. 
Table 2 Logistic regression analysis of determinants of early ANC attendance in PNG

\begin{tabular}{|c|c|c|c|c|}
\hline \multirow[t]{2}{*}{ Variable } & \multirow[b]{2}{*}{ AOR } & \multicolumn{2}{|l|}{$[95 \% \mathrm{Cl}]$} & \multirow[t]{2}{*}{$P$-value } \\
\hline & & Lower Bound & Upper Bound & \\
\hline \multicolumn{5}{|l|}{ Age } \\
\hline $15-19$ & Ref & Ref & Ref & Ref \\
\hline $20-24$ & 1.26 & 0.83 & 1.92 & 0.282 \\
\hline $25-29$ & 1.12 & 0.73 & 1.73 & 0.603 \\
\hline $30-34$ & 1.00 & 0.63 & 1.58 & 0.994 \\
\hline $35-39$ & 1.25 & 0.77 & 2.02 & 0.366 \\
\hline $40-44$ & 1.18 & 0.70 & 1.99 & 0.529 \\
\hline $45-49$ & 0.82 & 0.39 & 1.70 & 0.585 \\
\hline \multicolumn{5}{|l|}{ Wealth status } \\
\hline Poorest & Ref & Ref & Ref & Ref \\
\hline Poorer & 1.01 & 0.77 & 1.33 & 0.935 \\
\hline Middle & 0.97 & 0.74 & 1.28 & 0.847 \\
\hline Richer & 0.88 & 0.66 & 1.15 & 0.344 \\
\hline Richest & 0.81 & 0.60 & 1.08 & 0.143 \\
\hline \multicolumn{5}{|l|}{ Working status } \\
\hline Not working & Ref & Ref & Ref & Ref \\
\hline Working & 1.37 & 1.17 & 1.60 & $<0.001$ \\
\hline \multicolumn{5}{|l|}{ Educational level } \\
\hline No formal education & Ref & Ref & Ref & Ref \\
\hline Primary & 0.86 & 0.68 & 1.08 & 0.194 \\
\hline Secondary & 0.91 & 0.69 & 1.21 & 0.531 \\
\hline Higher & 1.26 & 0.83 & 1.91 & 0.278 \\
\hline \multicolumn{5}{|l|}{ Region } \\
\hline Southern region & Ref & Ref & Ref & Ref \\
\hline Highlands region & 1.14 & 0.93 & 1.39 & 0.202 \\
\hline Momase region & 0.91 & 0.74 & 1.13 & 0.41 \\
\hline Islands region & 0.50 & 0.40 & 0.62 & $<0.001$ \\
\hline \multicolumn{5}{|l|}{ Parity } \\
\hline 1 & Ref & Ref & Ref & Ref \\
\hline 2 & 0.96 & 0.76 & 1.20 & 0.692 \\
\hline 3 & 0.64 & 0.49 & 0.84 & 0.001 \\
\hline $4+$ & 0.79 & 0.61 & 1.04 & 0.088 \\
\hline \multicolumn{5}{|c|}{ Frequency if reading Newspaper/Magazine } \\
\hline Not at all & Ref & Ref & Ref & Ref \\
\hline Less than once a week & 0.83 & 0.67 & 1.02 & 0.072 \\
\hline At least once a week & 0.99 & 0.79 & 1.26 & 0.961 \\
\hline
\end{tabular}

Source: 2016-18 PDHS

Exponentiated coefficients; $95 \%$ confidence intervals [Cls] in square brackets ref reference, AOR Adjusted Odds Ratios

*Significant results in bold

Again, working women had higher odds of early ANC attendance compared to women who were not working. This is consistent with several empirical studies in various parts of the world such as Ghana [33], Nepal [34], Ethiopia [35, 36], and Nigeria [37,
38]. However, the results are different from the finding in the South African studies by Ebonwu et al. [11] and Solarin and Black [39] which showed that working women present late for their first ANC. The probable explanation they offered was that employed 
women were busy compared to those who are not working and as a result attend ANC in later part of their pregnancy duration.

It was also found that women in PNG with parity three had lower odds of early ANC initiation compared to those with parity one. This is in line with several previous studies [40-44] on the association between parity and ANC uptake, which consistently indicates that high parity is associated with late initiation and low uptake of antenatal care services. There are various possible pathways that studies have reported to show this association. For example, Dangal [45] has reported that successive pregnancies might carry lower risks for complications if the first pregnancy and birth were uncomplicated. Pallikadavath, Foss and Stones [46] have also indicated that women who do not experience any complication for a previous pregnancy might not see the need to seek early ANC during their current pregnancy. In addition, Simkhada et al. [42] and Pallikadavath, Foss and Stones [46] explained that some women with other children might be occupied with the responsibilities of taking care of them and might find it difficult to attend early ANC. Pell et al. [47] are also of the view that high parity women who have had previous successful pregnancies might think they are well 'experienced' and now used to the routine care offered during ANC and so might delay ANC initiation. In addition, Simkhada et al. [42] also stated that insufficient resources and deleterious experiences with ANC providers during earlier pregnancies might make women hesitant to seek early ANC in current pregnancies. The study also found that regional variations exist in the likelihood of early ANC attendance. Specifically, women in the Islands region had lower odds of early ANC attendance compared to those in the Southern regions. This is also consistent with previous studies which found that variations exist in the various regions and the uptake of antenatal care services [48-51]. The possible reasons for this could be differences in access to healthcare facilities among the regions and the level of socio-economic development.

\section{Strength and limitation of the study}

The study is fraught with certain limitations that demand acknowledging. First, the study design makes it impossible to draw causal interpretation on the findings obtained. Second, since the study demanded women to recall previous events, there is the possibility of social desirability and recall biases. Aside from these, the relatively large sample size and the use of nationally representative dataset could make the findings generalisable to women in their reproductive age in PNG. The study also employed various techniques to collect accurate data and there was a relatively high response rate during the data collection. The study also did extensive literature search in order to control for several factors associated with early ANC attendance.

\section{Conclusions}

This study found a relatively low prevalence of early ANC initiation among women in PNG. The factors associated with early ANC attendance were region of residence, parity, and working status of mothers. To increase early ANC uptake, these factors should be considered when designing new policies or reviewing policies and strategies on ANC uptake to help increase ANC attendance which can help in the reduction of maternal mortality.

\section{Abbreviations}

AOR: Adjusted Odds Ratio; Cl: Confidence Interval; VIF: Variance Inflation Factor; SDG: Sustainable Development Goal; ANC: Antenatal Care; WHO: World Health Organization

\section{Acknowledgements}

The author is grateful to MEASURE DHS project for giving him free access to the original dataset. The efforts of Mr. Ebenezer Agbaglo of the Department of English, University of Cape Coast, who copy-edited this manuscript are also acknowledged.

\section{Authors' contributions}

AS conceived and designed of study, AS analysed and/or interpreted the data. AS drafted the manuscript and revised the manuscript critically for important intellectual content. The author(s) read and approved the final manuscript.

\section{Funding}

The study did not receive any funding.

Availability of data and materials

The dataset can be accessed at https://dhsprogram.com/data/dataset/.

\section{Declarations}

\section{Ethics approval and consent to participate}

The 2016-2018 PDHS report indicated that ethical approval was granted by the ICF Institutional Review Board [18]. Both written and verbal informed consent were also sought from all the participants during the data collection exercise. We requested for the dataset on 10th March, 2020.The dataset can be accessed at: https://dhsprogram.com/data/dataset/Papua-New-Guinea_ Standard-DHS_2017.cfm?flag=0.

Consent for publication

Not applicable.

\section{Competing interests}

The authors declare that they have no competing interests.

Received: 16 December 2020 Accepted: 21 April 2021

Published online: 06 May 2021

\section{References}

1. WHO, UNICEF. UNFPA, the World Bank, United Nations: Trends in maternal mortality: 1990 to 2015; 2015.

2. Sageer R, Kongnyuy E, Adebimpe WO, Omosehin O, Ogunsola EA, Sanni B. Causes and contributory factors of maternal mortality: evidence from maternal and perinatal death surveillance and response in Ogun state, Southwest Nigeria. BMC Pregnancy Childbirth. 2019;19(1):63. 
3. Gebresilassie B, Belete T, Tilahun W, Berhane B, Gebresilassie S. Timing of first antenatal care attendance and associated factors among pregnant women in public health institutions of Axum town, Tigray, Ethiopia, 2017: a mixed design study. BMC Pregnancy Childbirth. 2019; 19(1):340.

4. World Health Organization (WHO). WHO Recommendations on Antenatal Care for a Positive Pregnancy Experience: Summary. Geneva: WHO; 2018. Addah A, Omietimi J, Allagoa D. Gestational age at first antenatal booking at the federal medical centre Yenagoa, Bayelsa State, South-South, Nigeria. Lancet. 2015;5(1):19-24.

5. World Health Organization. WHO Recommendations on Antenatal Care for a Positive Pregnancy Experience. World Health Organization; 2016.

6. Manyeh AK, Amu A, Williams J, Gyapong M. Factors associated with the timing of antenatal clinic attendance among first-time mothers in rural southern Ghana. BMC Pregnancy Childbirth. 2020;20(1):47.

7. Nieburg P. Improving Maternal Mortality and other aspects of women's health. Washington, DC: center for strategic and international studies; 2012.

8. Robbers G, Vogel JP, Mola G, Bolgna J, Homer CS. Maternal and newborn health indicators in Papua New Guinea-2008-2018. Sexual Reproductive Health Matters. 2019;27(1):52-68.

9. Williams C. Maternal deaths and their impact on children in Papua New Guinea. Aust N Z J Public Health. 2014;38:405-7.

10. Lincetto $\mathrm{O}$, Mothebesoane-Anoh S, Gomez P, Munjanja S. Antenatal care in Opportunities for Africa's Newborns.2006.

11. Moller AB, Petzold M, Chou D, Say L. Early antenatal care visit: a systematic analysis of regional and global levels and trends of coverage from 1990 to 2013. Lancet Global Health. 2017;5(10):e977-83.

12. Ebonwu J, Mumbauer A, Uys M, Wainberg ML, Medina-Marino A. Determinants of late antenatal care presentation in rural and peri-urban communities in South Africa: a cross-sectional study. PLoS One. 2018;13(3):1-16.

13. Wolde F, Mulaw Z, Zena T, Biadgo B, Limenih MA. Determinants of late initiation for antenatal care follow up: the case of northern Ethiopian pregnant women. BMC Res Notes. 2018;11(1):837.

14. Paudel YR, Jha T, Mehata S. Timing of first antenatal care (ANC) and inequalities in early initiation of ANC in Nepal. Front Public Health. 2017;5:242.

15. Wolde HF, Tsegaye AT, Sisay MM. Late initiation of antenatal care and associated factors among pregnant women in Addis Zemen primary hospital, South Gondar, Ethiopia. Reprod Health. 2019:16(1):73.

16. Ewunetie AA, Munea AM, Meselu BT, Simeneh MM, Meteku BT. DELAY on first antenatal care visit and its associated factors among pregnant women in public health facilities of Debre Markos town, North West Ethiopia. BMC Pregnancy Childbirth. 2018;18(1):173.

17. Alemu Y, Aragaw A. Early initiations of first antenatal care visit and associated factor among mothers who gave birth in the last six months preceding birth in Bahir Dar Zuria Woreda North West Ethiopia. Reprod Health. 2018;15(1):203.

18. Geta MB, Yallew WW. Early initiation of antenatal care and factors associated with early antenatal care initiation at health facilities in southern Ethiopia. Adv Public Health. 2017:2017:1-6.

19. National Statistical Office (NSO). [Papua New Guinea] and ICF Papua New Guinea Demographic and Health Survey 2016-18. Port Moresby, Papua New Guinea, and Rockville: NSO and ICF. 2019.

20. Gebremeskel F, Dibaba Y, Admassu B. Timing of first antenatal care attendance and associated factors among pregnant women in Arba Minch Town and Arba Minch District, Gamo Gofa Zone, South Ethiopia. J Environ Public Health. 2015;2015:1-7.

21. Kondale M, Tumebo T, Gultie T, Megersa T, Yirga $H$. Timing of first antenatal care visit and associated factors among pregnant women attending anatal clinics in Halaba Kulito governmental health institutions, 2015. J Women's Health Care. 2016;5(308):2167-0420.

22. Zegeye A, Bitew B, Koye D. Prevalence an determinants of early antenatal care visit among pregnant women attending antenatal care in Debre Birhan health institutions, Central Ethiopia. Afr J Reprod Health. 2013;17(4):133.

23. Ouendo E-M, Sossa JC, Saizonou J, Guedegbe C-CJ, Mongbo AV, Mayaki Al, et al. Determinants of low antenatal care services utilization during the first trimester of pregnancy in southern Benin rural setting. Univers J Public Health. 2015;3(5):220-8.

24. Karin G, Sandra A, Joanna RG, Brigit S. O. Timing of antenatal care for adolescent and adult pregnant women in South-Eastern Tanzania. BMC Pregnancy Childbirth. 2012;12:16.
25. Nicholas N, Kyei A, Oona M, Campbell R, Gabrysch S. The influence of distance and level of service provision on antenatal care use in rural Zambia. PLoS One. 2012;7(10):1 10.

26. Addah A, Omietimi J, Allagoa D. Gestational age at first antenatal booking at the federal medical centre Yenagoa, Bayelsa State, South-South, Nigeria. Lancet. 2015;5(1):19-24.

27. Athanase LGDM. A G. reported knowledge, attitude and practice of antenatal care services among women in Dodoma municipal, Tanzania. Pediatr Neonatal Care. 2014:4:1-8.

28. Damme TG, Workineh D, Gmariam A. Time of antenatal care booking and associated factors among pregnant women attending Ambo Town health facilities, Central Ethiopia. J Gynecol Obst. 2015;26(5):103.

29. Worku Takele W, Tariku A, Wagnew Shiferaw F, Demsie A, Alemu WG, Zelalem Anlay D. Anemia among Women Attending Antenatal Care at the University of Gondar Comprehensive Specialized Referral Hospital, Northwest Ethiopia, 2017. Anemia. 2018;2018.

30. Belayneh T, Adefris M, Andargie G. Previous early antenatal service utilization improves timely booking: cross-sectional study at university of Gondar hospital, northwest Ethiopia. J Pregnancy. 2014:2014:1-7.

31. Gulema H, Berhane Y. Timing of first antenatal care visit and its associated factors among pregnant women attending public health facilities in Addis Ababa, Ethiopia. Ethiop J Health Sci. 2017;27(2):139-46.

32. Tariku A, Melkamu Y, Kebede Z. Previous utilization of service does not improve timely booking in antenatal care: cross sectional study on timing of antenatal care booking at public health facilities in Addis Ababa. Ethiop J Health Dev. 2010;24(3):227-33.

33. Banchani E, Tenkorang EY. Occupational types and antenatal care attendance among women in Ghana. Health Care Women Int. 2014;35(7-9): 1040-64.

34. Pandey S, Karki S. Socio-economic and demographic determinants of antenatal care services utilization in Central Nepal. Int J MCH AIDS. 2011; 2(2):212.

35. Regassa N. Antenatal and postnatal care service utilization in southern Ethiopia: a population-based study. Afr Health Sci. 2011;11(3):390-7.

36. Assefa $\mathrm{E}$, Tadesse M. Factors related to the use of antenatal care services in Ethiopia: application of the zero-inflated negative binomial model. Women Health. 2017;57(7):804-21.

37. Akinyemi JO, Afolabi RF, Awolude OA. Patterns and determinants of dropout from maternity care continuum in Nigeria. BMC Pregnancy Childbirth. 2016;16(1):282.

38. Ononokpono DN. Maternal health care in Nigeria: Do community factors moderate the effects of individual-level Education and Ethnic origin? Af Popul Stud. 2015;16(1):1554-69.

39. Solarin I, Black V. "They told me to come back": women's antenatal care booking experience in inner-city Johannesburg. Maternal Child Health $\rfloor$. 2013;17(2):359- 67 .

40. Gitonga E. Determinants of focused antenatal care uptake among women in tharaka nithi county, Kenya. Adv Public Health. 2017;2017:1-4.

41. Agus $Y$, Horiuchi $S$. Factors influencing the use of antenatal care in rural West Sumatra, Indonesia. BMC Pregnancy Childbirth. 2012;12(1):9.

42. Simkhada B, Teijlingen ER, Porter M, Simkhada P. Factors affecting the utilization of antenatal care in developing countries: systematic review of the literature. J Adv Nurs. 2008:61(3):244-60.

43. Goldani MZ, Barbieri MA, Silva AA, Bettiol H. Trends in prenatal care use and low birthweight in southeast Brazil. Am J Public Health. 2004;94(8):1366-71.

44. Joshi C, Torvaldsen S, Hodgson R, Hayen A. Factors associated with the use and quality of antenatal care in Nepal: a population-based study using the demographic and health survey data. BMC Pregnancy Childbirth. 2014:14(1):94.

45. Dangal G. High-risk pregnancy. Int J Gynecol Obstet. 2007;8(2):2-13.

46. Pallikadavath S, Foss M, Stones RW. Antenatal care: provision and inequality in rural north India. Soc Sci Med. 2004:59(6):1147-58.

47. Pell C, Meñaca A, Were F, Afrah NA, Chatio S, Manda-Taylor L, Hamel MJ, Hodgson A, Tagbor H, Kalilani L, Ouma P. Factors affecting antenatal care attendance: results from qualitative studies in Ghana, Kenya and Malawi. PloS one. 2013:8(1):1-11.

48. Basha GW. Factors Affecting the Utilization of a Minimum of Four Antenatal Care Services in Ethiopia. Obstet Gynecol Int. 2019;2019:1-6.

49. Nketiah-Amponsah E, Senadza B, Arthur E. Determinants of utilization of antenatal care services in developing countries. Afr J Econ Manage Stud. 2013;10(1):1-10 
50. Ponna SN, Upadrasta VP, Geddam JB, Dudala SR, Sadasivuni R, Bathina H. Regional variation in utilization of Antenatal care services in the state of Andhra Pradesh. J Fam Med Prim Care. 2017;6(2):231.

51. Titaley CR, Dibley MJ, Roberts CL. Factors associated with underutilization of antenatal care services in Indonesia: results of Indonesia Demographic and Health Survey 2002/2003 and 2007. BMC Public Health. 2010;10(1):485.

\section{Publisher's Note}

Springer Nature remains neutral with regard to jurisdictional claims in published maps and institutional affiliations.

Ready to submit your research? Choose BMC and benefit from:

- fast, convenient online submission

- thorough peer review by experienced researchers in your field

- rapid publication on acceptance

- support for research data, including large and complex data types

- gold Open Access which fosters wider collaboration and increased citations

- maximum visibility for your research: over $100 \mathrm{M}$ website views per year

At $B M C$, research is always in progress.

Learn more biomedcentral.com/submissions 